\title{
Sexual and Bladder Dysfunction in Cauda Equina Syndrome: Correlation with Clinical and Urodynamic Studies
}

\author{
Gururaj Sangondimath, Abhinandan Reddy Mallepally, Amrithlal Mascharenhas, Harvinder Singh Chhabra \\ Department of Spine Services, Indian Spinal Injuries Centre, New Delhi, India
}

Study Design: Retrospective cohort study.

Purpose: To analyze the clinical and sphincteric outcomes and the extent of sexual dysfunction (SD) in subjects with cauda equina syndrome (CES) and to assess their correlation with patient-reported and clinical/urodynamic parameters.

Overview of Literature: Despite vast literature present for CES, extent of the problem of SD in CES patients has not received enough attention as reflected by the limited information in literature. Little is known about exact prevalence at presentation or about the recovery. A better understanding of SD and bladder dysfunction in CES secondary to lumbar disc herniation is essential as it commonly occurs in the sexually active age group.

Methods: All cases of cauda equine syndrome secondary to lumbar disc herniation were recruited. Biographical and clinical data, history, examination findings, operative variables, recovery, and SD were noted. Water cystometry and uroflowmetry were done preand postoperatively. The International Index of Erectile Function questionnaire and Female Sexual Function Index were used to assess SD among the men and women, respectively.

Results: A total of 43 patients with up to 2.94-year follow-up were included. Urodynamic studies were found to correlate significantly with age, days of bladder involvement, perianal numbness, and motor weakness $(p<0.01)$. In step-wise regression analysis, perianal sensation and overall motor weakness were bladder function determinants. Bladder function recovery was directly related to the number of delay days $(t=2.30, p<0.05)$ and with unilateral leg pain $(t=2.15, p<0.05)$. Significant correlation between SD with age and days of bladder involvement before surgery was found $(p<0.01)$.

Conclusions: Surgery timing is related to patient's functional and sexual outcomes. Patients with unilateral leg pain and hypocontractile bladder have better outcomes. SD is a remarkable problem in CES.

Keywords: Cauda equina syndrome; Sexual dysfunction; Urodynamic studies

\section{Introduction}

Cauda equina syndrome (CES) is a rare problem, with prevalence among patients with low back pain of ap- proximately four in 10,000 [1]. Mixter and Barr [2] firstly described CES attributing the neurological and urological symptoms to herniated lumbar disc, which causes cauda equina compression that requires urgent decompression.

Received Sep 16, 2019; Revised Jan 8, 2020; Accepted Jan 28, 2020

Corresponding author: Abhinandan Reddy Mallepally

Department of Spine Services, Indian Spinal Injuries Centre, Vasant Kunj, Sector C, New Delhi, Delhi 110070, India

Tel: +91-11-42255356, +91-8686598876, Fax: +91-11-26898810, E-mail: mabhi28@gmail.com 
Nearly $45 \%$ of CES cases in literature are attributed to herniated disc [3]. A total of $1 \%-2 \%$ of all disc herniations are known to progress to CES $[4,5]$.

Though the exact definition of CES is ambiguous, Fraser et al. [3] stated that it included at least one or more symptoms of loss of sensation in the saddle area, sphincter dysfunction (bladder and/or bowel), and/or sexual dysfunction (SD), often in combination with possible neurologic deficit in the lower limb (motor/sensory loss, reflex change). Despite the vast literature present for CES, the extent of SD problem in patients with CES has not received enough attention as reflected by the limited information in literature. Little is known about its exact prevalence at presentation or recovery [6,7]. Furthermore, its incidence and relation to clinical variables and investigations have not been studied in detail.

A better understanding of SD and bladder dysfunction in CES secondary to lumbar disc herniation is essential as it commonly occurs in the sexually active age group. The objectives of this study were to investigate SD and bladder dysfunction in patients who were operated for CES secondary to lumbar disc herniation, to find for correlation between SD and the clinical variables, and to ascertain the patients' wishes and potentials for establishing sexual contacts.

\section{Materials and Methods}

A retrospective analysis with prospective follow-up of our patients who were operated for CES secondary to lumbar disc herniation was performed. This study was by the institutional medical ethical committee of Indian Spinal Injuries Centre (IRB approval no., ISIC/RP/2015/060). Informed consent was obtained from all the individual participants included in the study. The hospital database was used to identify the cases, and subsequently, the files were reviewed. Preoperative variables regarding age (divided into groups of $<20,20-40,40-60$, and $>60$ years), gender, and clinical details about presence and duration of back ache, leg pain, lower limb numbness, weakness, perianal numbness, and bladder and bowel involvement were noted.

Clinical examination findings of the straight-leg raising test (SLR; graded as positive if $<70^{\circ}$ and negative if more than $70^{\circ}$ ), cross-leg SLR (graded as positive or negative), sensory deficit (graded as present or absent), motor deficit (graded according to the Medical Research Council), perianal numbness (graded as present or absent), and voluntary anal contraction (VAC; graded as present or absent) were also noted. Attention was particularly paid to sphincteric/detrusor function as reflected in the urodynamic studies (UDS; graded as acontractile, hypocontractile, or normal), which all patients had undergone preoperatively and at follow-up. All these clinical parameters were assessed on follow-up, and the extent of clinical recovery was noted.

Details of disc herniation as seen on magnetic resonance imaging, surgical procedure, and the patient's postoperative status were also noted. Preoperative and followup visual analogue scale scores and Oswestry Disability Index (ODI) scores were compared. The type of operative procedure done and the intraoperative complications were noted. Postoperative clinical parameters were re-assessed and compared with the preoperative parameters.

$\mathrm{SD}$ in men was analyzed using the International Index of Erectile Function (IIEF) questionnaire [8], which is a set of 15 questions, each of them being scored using a 5-point scale. A higher score indicates better sexual function. The questions are representative of the following five areas of sexual function: erectile function, desire, orgasmic function, intercourse satisfaction, and overall satisfaction. IIEF assessment is limited by its superficial assessment of psychosexual background and the very limited assessment of partner relationship, both of which are important factors in male SD presentation. Analysis of the questionnaire should, therefore, be viewed as an adjunct to, rather than a substitute for, a detailed sexual history and examination. Each area of sexual activity was scored separately, and a general score of sexual function was obtained by adding the individual scores. SD in the individual areas and the total scores was categorized as absent, mild, moderate, or severe.

Female SD was analyzed using the Female Sexual Function Index (FSFI) questionnaire [9]. FSFI consists of the following six individual domains: desire, arousal, orgasm, pain, lubrication, and satisfaction. Each domain has a maximum score of 6 points and a minimum score of 0 , except desire (1.2) and satisfaction (0.8). Summation of the individual scores could yield a minimum score of 2 points and a maximum of 36 points. A score of less than 26.55 was considered as a dysfunction [3]. These scores were correlated with the preoperative and postoperative clinical variables and UDS.

The extent of SD was compared with age, gender, symp- 
toms, clinical recovery, bladder function recovery, UDS evaluation, and duration of stay in hospital. The number of subjects evaluated for their SD by urologists and the treatments recommended and its effects were also noted.

Correlations between the total sexual function score and the patients' age, neural damage duration, and clinical findings were assessed with nonparametric Spearman's correlation coefficient. The effects of age, etiology, duration and level of neural lesion, perianal sensation (PAS), and sexual function (erectile function, intercourse satisfaction, orgasmic function, sexual desire, and overall satisfaction) on the general score of sexual function were also analyzed using multiple linear regression analysis. Mean \pm standard deviation, $t$-test, and paired $t$-test were calculated. Statistical analysis was done using IBM SPSS Statistics ver. 23.0 software (IBM Corp., Armonk, NY, USA).

\section{Results}

A total of 59 patients with CES owing to lumbar disc herniation who satisfied our inclusion criteria were enrolled. A total of 43 (33 men, 10 women) of them were followed up. The mean follow-up duration was 2.94 years (range, 1 to 6.9 years). The patients' mean age was 43.4 years ( 42.6 years in men, 46.1 years in women; range, 20 to 72 years). There were two patients below the age of 20 years, 16 between 20 and 40 years, 20 between 40 and 60 years, and five above 60 years.

There were 38 patients (88.4\%) and five patients (11.6\%) who had backache and no backache, respectively. The average backache duration was 386 days (range, 1 to 10 years). A total of 15 patients had backache on followup. A remarkable improvement on back pain pre- and postoperatively $(t=5.95, p<0.01)$ was found. A total of 43 patients had leg pain, of whom $12(27.9 \%)$ had unilateral radicular pain whereas $31(72.1 \%)$ had bilateral radicular pain. The average leg pain duration was 186 days (range, 1 to 6 years). Seven patients continued to have leg pain in the follow-up.

There were 41 patients who had perianal numbness preoperatively and only 26 at follow-up. The average perianal

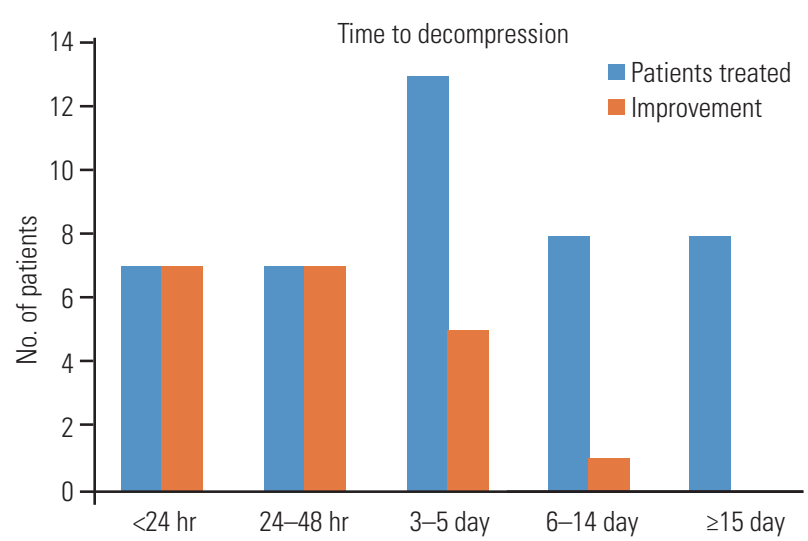

Fig. 1. Graph showing bladder function improvement in relation to surgery timing in patients with cauda equina syndrome.

Table 1. Comparison of pre- and postoperative variables using paired $t$-test

\begin{tabular}{|c|c|c|c|}
\hline Variable & Preoperative & Postoperative & $t$-value \\
\hline Back pain ( $1=$ present, $0=$ absent) & $0.88 \pm 0.32$ & $0.35 \pm 0.48$ & $5.93^{* *}$ \\
\hline Straight-leg raising ( $1=$ positive, $0=$ negative) & $0.86 \pm 0.35$ & $0.02 \pm 0.15$ & $12.69 * *$ \\
\hline Motor weakness ( $1=$ present, $0=$ absent) & $0.77 \pm 0.43$ & $0.37 \pm 0.49$ & $3.93^{* *}$ \\
\hline Perianal sensation ( $1=$ present, $0=$ absent) & $0.09 \pm 0.29$ & $0.56 \pm 0.5$ & $6.04^{* *}$ \\
\hline Voluntary anal contraction ( $1=$ present, $0=$ absent) & $0.07 \pm 0.26$ & $0.28 \pm 0.45$ & $2.46^{*}$ \\
\hline Urodynamic-study (1=normal, $0=$ abnormal) & 0 & $0.58 \pm 0.5$ & $7.64^{* *}$ \\
\hline Oswestry Disability Index (scale of 0-100) & $64.95 \pm 9.29$ & $9.44 \pm 11.2$ & $28.29 * *$ \\
\hline Visual Analog Scale-back pain (scale of 0-10) & $6.72 \pm 1.67$ & $0.79 \pm 1.13$ & $20.26^{* *}$ \\
\hline Visual Analog Scale-leg pain (scale of 0-10) & $7.33 \pm 1.74$ & $0.72 \pm 1.12$ & $22.75^{* *}$ \\
\hline Bulbocavernosus reflex ( $1=$ present, $0=a b s e n t)$ & $0.93 \pm 0.26$ & $0.67 \pm 0.47$ & $2.89 * *$ \\
\hline Perianal numbness ( $1=$ present, $0=$ absent $)$ & $0.95 \pm 0.21$ & $0.6 \pm 0.5$ & $4.32^{* *}$ \\
\hline Duration of numbness (day) & $0.95 \pm 0.21$ & $0.93 \pm 0.26$ & 1.00 (NS) \\
\hline
\end{tabular}

Values are presented as mean \pm standard deviation.

NS, not significant.

$p<0.05 .{ }^{* *} p<0.01$. 
numbness duration was 24 days (range, 1 to 365 days). This difference was found to be statistically significant $(t=4.32, p<0.01)$ (Fig. 1).

A total of 41 patients had lower limb numbness, with average duration at 32 days (range, 1 to 365 days), of whom three were unilateral and 38 bilateral. At followup, 27 patients had sensory deficits in the lower limbs. This difference was not found to be statistically significant $(t=1.00, p>0.05)$. A total of 37 patients had root tension sign, which was signified by a positive SLR only in one patient during follow-up. This difference was found to be statistically significant $(t=12.69, p<0.01)$. Furthermore, 40 patients had a weak or absent VAC, whereas three were normal. Moreover, during follow-up, 32 had weak VAC, 11 had normal VAC, and none had absent VAC. This difference was found to be statistically significant $(t=-2.46$, $p<0.05)$.

There were 38 patients who had experienced lower limb weakness, with average duration at 19.46 days (range, 1 to 365 days). Of these, only 34 patients were found to have objective lower limb weakness, eight of whom were unilateral and 26 bilateral (Table 1).

All patients had changes in UDS, consistent with detrusor involvement as seen in CES. There were 25 who had acontractile detrusor, whereas the rest had hypocontractile detrusor. Furthermore, there were seven patients operated within 24 hours of bladder symptom onset, seven between 24 and 48 hours, 13 between 3 and 5 days, eight between 6 and 14 days, and eight after 15 days. Moreover, 20 patients still had bladder dysfunction at follow-up revealed even on UDS (Fig. 1). This difference was found to be statistically significant $(t=-5.20, p<0.01)$. The type of surgical procedure done is found in Table 2 .

The average duration from the time of bowel involvement up to the time of surgery was 26.2 days (range, 1 to 365 days). One patient had no bowel symptoms, whereas the rest had anal incontinence. Furthermore, 18 patients had symptomatic bowel disturbance at follow-up. The av-

Table 2. Table exhibiting type of surgical procedure underwent by the patients

\begin{tabular}{lccc} 
Variable & $\begin{array}{c}\text { No. of } \\
\text { patients }\end{array}$ & $\begin{array}{c}\text { Mean } \pm \text { standard } \\
\text { deviation }\end{array}$ & $t$-value \\
Type of surgery & & & 1.07 (NS) \\
Discectomy & 27 & $0.52 \pm 0.50$ & \\
Instrumented fusion & 16 & $0.69 \pm 0.47$ & \\
\hline
\end{tabular}

NS, not significant. erage duration of hospital stay was 11.04 days (range, 3 to 30 days).

There were 36 cases who had 1-level compression, six 2-level compression, and one 3-level compression. The most common level involved was the L4-5 with 22 cases, followed by L5-S1 with 11 patients, L3-4 with eight patients, and L2-3 with two. In cases of more than one level of compression, the most remarkable noted intraoperatively by the operating surgeon was taken as the level of compression.

Age correlated significantly with $\mathrm{SD}(p<0.01)$ as assessed by Pearson's correlation coefficient. In men, the individual domains of orgasm, sexual satisfaction, and overall satisfaction correlated with age $(p<0.05)$. In women, all individual domains except desire correlated significantly with age $(p<0.05)$. Bladder involvement duration correlated significantly with SD $(p<0.01)$. Patients who had longer bladder involvement were found to be associated with SD (Fig. 2).

All the male patients were asked to answer the IIEF questionnaire, and the individual domain and total scores were analyzed. Of the 33 male patients, SD was noted in 23 (70\%) (mean score, 37.1), whereas 10 (30\%) had no dysfunction (mean score, 67.4). Distribution of the total scores revealed SD to be severe in $6(18.2 \%)$ (mean score, 19.7), moderate in 7 (21.1\%) (mean score, 34.3), and mild in 10 (30.3\%) (mean score, 49.6). The minimal clinically important differences for decrease in IIEF in men was 1.61. There was significant correlation between total scores and bladder involvement duration $(p<0.01)$ and VAC $(p<0.05)$. Erectile dysfunction (mean score, 15.7) was found to be mild in eight patients (mean score, 22.5), moderate in nine (mean score, 14), and severe in four (mean score, 6). Furthermore, it had significant correlation $(p<0.01)$ with

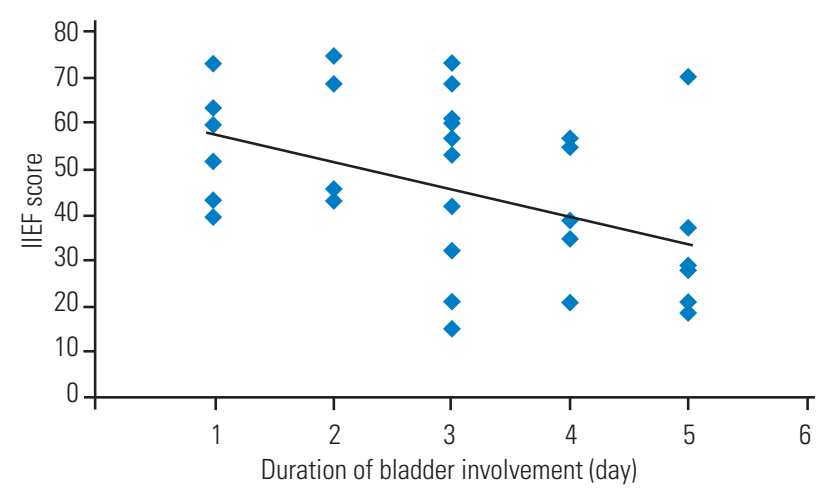

Fig. 2. Graph showing correlation between sexual dysfunction and duration of bladder symptoms. IIEF, International Index of Erectile Function. 
days of bladder involvement before surgery. Orgasmic dysfunction (mean score, 3.8) was found to be mild in five (mean score, 7.5), moderate in six (mean score, 4.7), and severe in 12 patients (mean score, 1.75). Furthermore, it had significant correlation with age $(p<0.05)$, bowel involvement at follow-up $(p<0.05)$, VAC $(p<0.05)$, and Visual Analog Scale-back pain $(p<0.05)$. Dysfunction in desire (mean score, 5.5) was found to be mild in eight (mean score, 7.5), moderate in four (mean score, 5.5), and severe in eight (mean score, 3.25). It was also significantly associated with age $(p<0.05)$, duration to operation from onset of bladder symptoms (DOBLD) $(p<0.05)$, PAS $(p<0.01)$, bowel involvement at follow-up $(p<0.05)$, and VAC $(p<0.05)$. Dysfunction in sexual intercourse satisfaction (mean score, 4.3) was mild in four (mean score, 9.25), moderate in nine (mean score, 5.3), and severe in nine patients (mean score, 1.1). It correlated significantly with age $(p<0.05)$, DOBLD $(p<0.05)$, and PAS $(p<0.05)$. Dysfunction in overall satisfaction was mild in five (mean score, 7.4), moderate in seven (mean score, 5.3), and severe in 11 patients (mean score, 2.7). Furthermore, it had significant correlation with DOBLD $(p<0.05)$ and VAC $(p<0.05)$ (Tables 3, 4).

Of the 10 female patients, SD was noted in $6(60 \%)$ (mean score, 4.6), of whom five had not had sexual intercourse in the last month of follow-up. These five patients had minimum scores in each of the subdomains. In the sixth patient, the subdomains of lubrication (score, 2.4) and satisfaction (score, 2.4) were most affected, followed by arousal (score, 2.7) and orgasm (score, 2.8), with desire (score, 3.0) and pain (score, 4.4) the least affected. Four patients had no dysfunction (mean score, 28.55). The only variable that correlated with SD was age $(p<0.05)$. The more elderly age group was found to be more affected by SD (Fig. 3). Of the six patients in the SD group, three had bladder dysfunction, which was proved by UDS, whereas the other two had normal bladder function, one of whom had a high postoperative ODI score owing to backache and the other was an elderly and had lost the desire for sex after CES. One patient who had a score marginally below normal also had bladder dysfunction. Among the patients with no SD, two had abnormal UDS findings whereas two

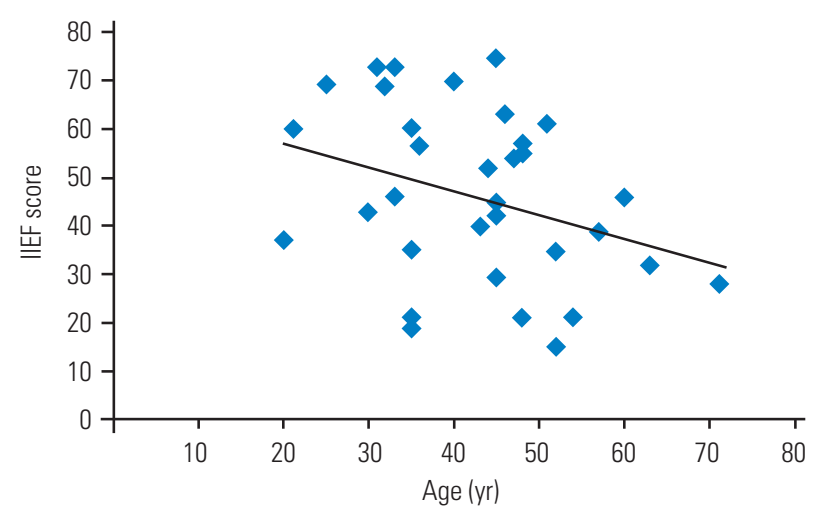

Fig. 3. Graph showing correlation between sexual dysfunction (IIEF score) and patient's age. IIEF, International Index of Erectile Function.

Table 3. Comparison of variables and correlation between IIEF scores with age and bladder dysfunction

\begin{tabular}{llllcccc} 
Variable & IIEF & $\begin{array}{c}\text { Erectile } \\
\text { function }\end{array}$ & $\begin{array}{c}\text { Orgasmic } \\
\text { function }\end{array}$ & $\begin{array}{c}\text { Sexual desire } \\
\text { function }\end{array}$ & $\begin{array}{c}\text { Intercourse } \\
\text { satisfaction }\end{array}$ & $\begin{array}{c}\text { Overall } \\
\text { satisfaction }\end{array}$ & Total IIEF score \\
\hline Age $(y)^{\text {a) }}$ & 0.3075 & -0.0624 & $-0.4049^{*}$ & $-0.5459^{*}$ & $-0.3779^{*}$ & -0.3371 & -0.3372 \\
DOBLD $^{\text {b) }}$ & $0.4977^{* *}$ & $-0.4540^{* *}$ & -0.3368 & $-0.3611^{*}$ & $-0.3810^{*}$ & $-0.4268^{* *}$ & $-0.4461^{* *}$ \\
\hline
\end{tabular}

IIEF, International Index of Erectile Function; DOBLD, duration to operation from onset of bladder symptoms.

"Significant at $p<0.05$ level. "* Significant at $p<0.01$ level. ${ }^{\text {a) }}$ Age group (yr): $<20,20-40,41-60$, and $>60$. ${ }^{\text {bl}} D 0 \mathrm{BLD}$ group: $<24 \mathrm{hr}, 24-48 \mathrm{hr}, 3-5$ day, $6-15$ day, and $>15$ day.

Table 4. Comparison of variables and correlation between IIEF scores and other parameters

\begin{tabular}{lccccccc} 
Variable & IIEF & $\begin{array}{c}\text { Erectile } \\
\text { function }\end{array}$ & $\begin{array}{c}\text { Orgasmic } \\
\text { function }\end{array}$ & $\begin{array}{c}\text { Sexual desire } \\
\text { function }\end{array}$ & $\begin{array}{c}\text { Intercourse } \\
\text { satisfaction }\end{array}$ & $\begin{array}{c}\text { Overall } \\
\text { satisfaction }\end{array}$ & $\begin{array}{c}\text { Total IIEF } \\
\text { score }\end{array}$ \\
Bowel dysfunction (1=present, $0=$ absent) & 0.2755 & -0.3079 & $-0.3747^{*}$ & $-0.3513^{*}$ & -0.302 & -0.3051 & -0.3247 \\
\hline Perianal sensation (1=present, $0=$ absent) & -0.294 & 0.1595 & 0.2278 & $0.4385^{* *}$ & $0.3575^{*}$ & $0.3688^{*}$ & 0.2768 \\
Voluntary anal contraction (1=present, 0=absent) & 0.3152 & -0.1427 & $-0.3673^{*}$ & $-0.3910^{*}$ & -0.3363 & $-0.3831^{*}$ & $-0.3562^{*}$ \\
\hline Visual Analog Scale-back pain (scale 0-10) & 0.2369 & -0.1857 & $-0.4231^{*}$ & -0.1219 & -0.2744 & $-0.3914^{*}$ & -0.3331 \\
\hline
\end{tabular}

IIEF, International Index of Erectile Function.

"Significant at $p<0.05$ level. ${ }^{* *}$ Significant at $p<0.01$ level. 
had normal bladder functions. The total and all individual domain scores of FSFI except desire had remarkable correlation with age. Nevertheless, there was no remarkable correlation regarding duration of bladder dysfunction before surgery, sensory numbness, postoperative UDS, and any other pre- or postoperative variables. Of the total 43 cases, 29 (67\%) had SD based on the IIEF and FSFI questionnaires, and these patients had remarkable correlation with age and duration of bladder involvement before surgery.

\section{Discussion}

CES is a rare and potentially disabling condition with remarkable medical and social morbidity. It is also associated with remarkable medico-legal workload and costs $[10,11]$. Although the diagnosis is mostly performed on clinical grounds, it lacks sensitivity and specificity [12]. Magnetic resonance or computed tomography imaging demonstrates the exact location of compression and its causal element.

Urgent surgical decompression by the offending material is the only effective measurement in CES. At present, there is substantial evidence that surgical decompressive procedures $<48$ hours yield remarkably better results than those $>48$ hours [13]. Available evidence in literature regarding CES is mainly concerned about bladder outcomes, motor function, general quality of life, and back or leg pain. Details about outcomes of defecation and/ or sexual function are only marginally described, even though they are, by definition, often impaired in patients with CES $[6,14,15]$. Also, guideline review in CES was not mentioned [16].

Micturition, defecation, and especially sexual function are topics of uncertainty owing to embarrassment and resistance to discuss the symptoms by the patients $[3,6]$. Also, dearth in prognostic data leads the patient to a position of maximum concern. This study aims to evaluate the outcome of CES after decompressive surgery with particular interest in micturition, defecation, and sexual function and the attitude of patients with CES toward delivered hospital care before and after decompressive surgery.

Very few authors have addressed the issue of SD in CES owing to lumbar disc herniation. The existing literature has not analyzed the different aspects of SD. Only two studies have tried to find a correlation between different clinical variables and SD by systematic statistical analy- sis. Few CES outcome studies have shown rates of SD greater than $50 \%$ at a mean of 2 months, 5 years, and 14 years of follow-up [16-18]. A meta-analysis revealed an overall rate of $43 \%$ in 322 patients [13]. Nevertheless, no study has evaluated correlation by urodynamic testing. To the best of our knowledge, this is the largest series on the study of SD in CES that is purely owed to lumbar disc herniation. It has been conducted in a specialized spinal unit with sufficiently long follow-up. Gleave and MacFarlane [19] reported that SD appeared to mirror sphincter outcome.

Nevertheless, their study was not based on objective UDS or involved detailed assessment by standard questionnaires. In our objective analysis by UDS and SD questionnaires, we found no correlation between sphincter functions and SD. Our finding of good correlation between duration of bladder dysfunction preoperatively with SD suggests that the patients might benefit from early decompression. This is supported by Hellström et al. [20] and Shapiro [21] who suggested early decompression to avoid SD. McCarthy et al. [18] found no correlation between SD and age, but our study proves that there is a remarkable correlation between age and SD, which is consistent by the meta-analysis of Ahn et al. [13] .

Podnar et al. [22], with their clinical and electromyography study, reported on sexual function in men with cauda equina lesions. They had used the IIEF questionnaire and found that $35 \%, 24 \%$, and $26 \%$ cases had severe, moderate, and mild dysfunction, respectively. Normal sexual function was found in $15 \%$ of the cases. They also found orgasmic function to be the most affected, followed by erectile function and sexual desire. They found SD to be correlated only with age and not with any other variable, including electromyography. In our series, we found $18.1 \%, 21.2 \%$, and $30.3 \%$ of men to have severe, moderate, and mild dysfunction, respectively. Normal function was seen in $30.4 \%$ cases. Our patients seem to be doing better than those in series of Podnar et al. [22]. This could be probably explained by the fact that their cases were of a long duration without emergent surgical management in many of the cases. They also had included cases of varied etiologies and even lesions of the conus medullaris, with some wheelchair-bound or in need of external supports for mobilization. In comparison, our cases are from a tertiary spine center that mostly deals with acute management of CES. We have included a uniform group of patients regarding etiology and CES level. Furthermore, 
none of our cases were wheelchair-dependent or in need of external support for mobilization.

Most series have anecdotal reports on the issue of female SD in patients with CES owing to lumbar disc herniation. We found that $60 \%$ of our female patients suffered from SD, and it correlated remarkably with the patient's age. This study is the most comprehensive to date on the issue of SD in CES owing to lumbar disc herniation. We find it to be a remarkable problem in both men and women. In our series, many patients were found to have suffered from SD. Longer duration of bladder involvement is associated with persistent SD at follow-up. SD is a poorly addressed issue in CES, and more research is required in this matter.

Because this is a retrospective analysis, it has some inherent drawbacks. Preoperative sexual history could not be obtained in most cases. This is partly due to the acute nature of the pathology and the associated pain involved that the patient does not involve in any sexual experience during this time period. Nevertheless, all our patients have stated that they have had sufficient function before the onset of symptoms. In our study, we have had a smaller number of female subjects making it difficult to apply statistical tools for analysis. There are no partner report or laboratory observations of individual domains of sexual function. Some patients may not want to reveal their sexual inadequacies.

\section{Conclusions}

Surgery timing is related to functional and sexual outcomes of patients as early decompression may help in regaining sexual functions. Patients with unilateral leg pain and hypocontractile bladder have better outcomes in bladder function. Every patient must be counseled regarding SD before and after surgery.

\section{Conflict of Interest}

No potential conflict of interest relevant to this article was reported.

\section{References}

1. Deyo RA, Rainville J, Kent DL. What can the history and physical examination tell us about low back pain? JAMA 1992;268:760-5.
2. Mixter WJ, Barr JS. Rupture of the intervertebral disc with involvement of the spinal canal. N Engl J Med 1934;211:210-5.

3. Fraser S, Roberts L, Murphy E. Cauda equina syndrome: a literature review of its definition and clinical presentation. Arch Phys Med Rehabil 2009;90:19648.

4. Jennett WB. A study of 25 cases of compression of the cauda equina by prolapsed intervertebral discs. J Neurol Neurosurg Psychiatry 1956;19:109-16.

5. O'Laoire SA, Crockard HA, Thomas DG. Prognosis for sphincter recovery after operation for cauda equina compression owing to lumbar disc prolapse. Br Med J (Clin Res Ed) 1981;282:1852-4.

6. Korse NS, Jacobs WC, Elzevier HW, VleggeertLankamp CL. Complaints of micturition, defecation and sexual function in cauda equina syndrome due to lumbar disk herniation: a systematic review. Eur Spine J 2013;22:1019-29.

7. Tamburrelli FC, Genitiempo M, Bochicchio M, Donisi L, Ratto C. Cauda equina syndrome: evaluation of the clinical outcome. Eur Rev Med Pharmacol Sci 2014;18:1098-105.

8. Rosen RC, Riley A, Wagner G, Osterloh IH, Kirkpatrick J, Mishra A. The International Index of Erectile Function (IIEF): a multidimensional scale for assessment of erectile dysfunction. Urology 1997;49:82230.

9. Wiegel M, Meston C, Rosen R. The Female Sexual Function Index (FSFI): cross-validation and development of clinical cutoff scores. J Sex Marital Ther 2005;31:1-20.

10. Todd NV. Causes and outcomes of cauda equina syndrome in medico-legal practice: a single neurosurgical experience of 40 consecutive cases. Br J Neurosurg 2011;25:503-8.

11. Quraishi NA, Hammett TC, Todd DB, Bhutta MA, Kapoor V. Malpractice litigation and the spine: the NHS perspective on 235 successful claims in England. Eur Spine J 2012;21 Suppl 2(Suppl 2):S196-9.

12. Germon T, Ahuja S, Casey AT, Todd NV, Rai A. British Association of Spine Surgeons standards of care for cauda equina syndrome. Spine J 2015;15(3 Suppl):S2-4.

13. Ahn UM, Ahn NU, Buchowski JM, Garrett ES, Sieber AN, Kostuik JP. Cauda equina syndrome secondary to lumbar disc herniation: a meta-analysis of surgical 
outcomes. Spine (Phila Pa 1976) 2000;25:1515-22.

14. Ma B, Wu H, Jia LS, Yuan W, Shi GD, Shi JG. Cauda equina syndrome: a review of clinical progress. Chin Med J (Engl) 2009;122:1214-22.

15. Korse NS, Pijpers JA, van Zwet E, Elzevier HW, Vleggeert-Lankamp CL. Cauda equina syndrome: presentation, outcome, and predictors with focus on micturition, defecation, and sexual dysfunction. Eur Spine J 2017;26:894-904.

16. Todd NV. Guidelines for cauda equina syndrome: red flags and white flags: systematic review and implications for triage. Br J Neurosurg 2017;31:336-9.

17. Korse NS, Veldman AB, Peul WC, VleggeertLankamp CL. The long term outcome of micturition, defecation and sexual function after spinal surgery for cauda equina syndrome. PLoS One 2017;12:e0175987.
18. McCarthy MJ, Aylott CE, Grevitt MP, Hegarty J. Cauda equina syndrome: factors affecting long-term functional and sphincteric outcome. Spine (Phila Pa 1976) 2007;32:207-16.

19. Gleave JR, MacFarlane R. Prognosis for recovery of bladder function following lumbar central disc prolapse. Br J Neurosurg 1990;4:205-9.

20. Hellstrom P, Kortelainen P, Kontturi M. Late urodynamic findings after surgery for cauda equina syndrome caused by a prolapsed lumbar intervertebral disk. J Urol 1986;135:308-12.

21. Shapiro S. Cauda equina syndrome secondary to lumbar disc herniation. Neurosurgery 1993;32:743-6.

22. Podnar S, Oblak C, Vodusek DB. Sexual function in men with cauda equina lesions: a clinical and electromyographic study. J Neurol Neurosurg Psychiatry 2002;73:715-20. 